\title{
Financiamento de mídia alternativa no Brasil
}

\section{RCD)}

Alternative media funding in Brazil

\section{Eleonora de Magalhães Carvalho ${ }^{1}$}

\begin{abstract}
Resumo: Este trabalho discute o financiamento da mídia alternativa no Brasil, tendo como objeto a chamada Blogosfera Progressista. O artigo propõe duas amplas categorias principais de financiamento: estratégias de autofinanciamento, que incluem "vaquinhas coletivas" (crowdfunding) e venda de assinaturas, entre outras; e financiamento via fontes externas ao blog, site ou outra categoria de iniciativa midiática, por meio de recursos provenientes de verbas públicas ou da iniciativa privada, seja ela empresarial ou fruto de subvenção concedida por instituições de fomento, em geral, internacionais. O trabalho conclui que a questão do financiamento se faz importante porque, além de nutrir um ecossistema midiático plural, impacta efetivamente no alcance que cada uma das iniciativas midiáticas alternativas pode ter no sistema midiático do qual faz parte, estimulando o debate público e favorecendo, potencialmente, a qualidade das democracias.
\end{abstract}

Palavras-chave: Financiamento. Mídia alternativa. Democracia. Internet.

\begin{abstract}
This paper discusses the financing of alternative media in Brazil, having as its object the so-called Progressive Blogosphere. The article proposes two broad categories of funding: self-financing strategies, which include crowdfunding and subscriptions, among others; and financing via sources external to the blog, website or other category of media initiative, through resources from public funding or private initiative. The work concludes that the question of funding is important because, in addition to nurturing a plural media ecosystem, it effectively impacts the reach that each of the alternative media initiatives can have in the media system of which it is a part, stimulating public debate and, potentially favouring the quality of democracies.
\end{abstract}

Keywords: Funding. Alternative media. Democracy. Internet.

\section{Introdução}

A internet contribuiu para o desenvolvimento de um novo campo do exercício de jornalismo. No que tange a projetos de mídia alternativa, a economia de recursos (financeiros, materiais, humanos e de tempo) proporcionada pela web fez com que um crescente número de meios de comunicação passasse a integrar o sistema midiático mundial, principalmente a partir dos anos 2000. O aspecto mercadológico foi um dos fatores que contribuiu para a entrada de novos agentes no cenário midiático brasileiro (DE MAGALHÃES CARVALHO, 2018). Além da questão econômica, porém, há motivações outras que envolvem, no fim das con-

\footnotetext{
Doutora e Mestra em Comunicação pelo Programa de Pós-Graduação em Comunicação da Universidade Federal Fluminense (UFF). Atualmente trabalha como professora do curso de Jornalismo da Faculdade Pinheiro Guimarães e é pesquisadora do Laboratório de Democracia da UFF (Lamide/UFF).
} 
tas, disputas políticas. Anos antes da eleição de Trump, nos Estados Unidos, e do processo de impeachment contra a presidente Dilma Rousseff e da eleição de Jair Bolsonaro, no Brasil, agentes midiáticos considerados periféricos desempenharam (e ainda desempenham) papel importante na cobertura política, expandindo as formas de circulação da informação.

Do ponto de vista estratégico, blogs e outros veículos de mídia alternativa conquistaram protagonismo, mesmo que, por vezes, restrito a nichos ou "bolhas ideológicas". Pelo prisma da economia política da comunicação, o financiamento dessas iniciativas está, em última análise, estreitamente ligado à democratização da mídia e à qualidade da própria democracia de uma país, dado que a pluralidade de pontos de vista, sobretudo aqueles contra-hegemônicos, tem a capacidade de estimular o debate público (cf. DOWNING, 2001; FUCHS, 2010). Nesse sentido, entre os anos de 2005 e 2010, no Brasil, começa a ganhar força um movimento de blogueiros que foi capaz de transformar o jornalismo político em elemento unificador de agentes desiguais, que se articularam em torno de um projeto comum que reivindica possuir não apenas um papel de imprensa, mas condições para seu desenvolvimento em um cenário midiático pouco democrático e altamente concentrado nas mãos de algumas famílias e empresários do ramo da comunicação. Nesse sentido, a Blogosfera Progressista brasileira (doravante BP) representa um cenário original dentro do contexto de renovação do jornalismo, formada por blogs, sites, portais e outras formas de existência on-line, apresentando a defesa da democratização das comunicações no país como principal bandeira levantada por seus componentes (cf. DE MAGALHÃES CARVALHO, 2017; GUAZINA, 2013).

Observa-se que, no período em que a BP florescia, cinco grupos, em sua maioria empresas familiares, detinham a posse dos principais canais de comunicação de mídia com abrangência nacional: Editora Abril (família Civita), Grupo Bandeirantes (família Saad), Grupo Folha (dos Frias), Grupo Silvio Santos (comandado pela família Abravanel) e Organizações Globo (dos Marinho). A concentração midiática no Brasil perpetuou-se inclusive durante os governos petistas (DE MAGALHÃES CARVALHO, 2020), traduzindo-se em concentração de investimentos, via recursos públicos, nesses poucos grupos de mídia que, em geral, se vinculam a perspectivas economicamente liberais. Agentes com os quais os blogueiros progressistas se colocaram em rota de colisão ao elegerem a democratização e desconcentração das comunicações como problemas centrais, tematizando o fınanciamento midiático como questão chave. 


\section{Considerações metodológicas}

A discussão aqui apresentada possui como recorte temporal, para a apresentação de dados, os anos das administrações petistas à frente da Presidência da República. Foi um período que coincidiu com o avanço da comunicação em rede no Brasil e cujo contexto contribuiu para o surgimento de uma nova ecologia midiática, a partir do fenômeno Blogosfera Progressista brasileira.

Neste trabalho, seguiremos o mapeamento desenvolvido por De MagaIhães Carvalho (2017) em sua tese sobre esse ecossistema midiático em particular para definir nossa amostragem de blogs/sites estudados. Parte do material utilizado neste trabalho foi obtida a partir de fontes primárias, por meio de entrevistas realizadas entre outubro de 2016 e maio de 2017, com os entrevistados representando, ao menos em parte, já que se trata de um ecossistema absolutamente complexo, a heterogeneidade da BP (GUAZINA, 2013; ALBUQUERQUE; DE MAGALHÃES CARVALHO, 2017).

Nesse sentido, conversamos com: Luis Nassif, Luiz Carlos Azenha, Renato Rovai, Altamiro Borges, Paulo Henrique Amorim e Miguel do Rosário - "blogueiros progressistas" que também nos ajudam a entender inclusive os diferentes graus de institucionalização e arranjos organizativos dos empreendimentos midiáticos desse segmento alternativo (Tabela 1). Eles responderam a um questionário com perguntas abertas elaboradas pela autora, direcionado e adaptado a cada um dos entrevistados, conforme suas especificidades. Dentre as questões que versavam sobre a experiência profissional do entrevistado (anterior e posteriormente à sua entrada na blogosfera) e seu envolvimento e/ou identificação com movimentos de esquerda e a própria BP, estavam aquelas relativas às formas de financiamento do blog/site. Os demais dados relativos a financiamento foram coletados, quando disponíveis, nos próprios meios de comunicação e/ou junto às respectivas organizações financiadoras. 
Tabela 1 - Amostragem de entrevistados da BP

\begin{tabular}{|c|c|c|}
\hline ENTREVISTADO & MÍDIA ALTERNATIVA & ANO DE FUNDAÇÃO \\
\hline \multirow{3}{*}{ Altamiro Borges $^{2}$} & Blog do Miro & \\
\hline & $\begin{array}{l}\text { Centro de Estudos da } \\
\text { Mídia Alternativa Barão de } \\
\text { Itararé }\end{array}$ & 2008 \\
\hline & $\begin{array}{l}\text { Centro de Estudos da } \\
\text { Mídia Alternativa Barão de } \\
\text { Itararé }\end{array}$ & 2010 \\
\hline \multirow{2}{*}{ Luis Nassif } & $\begin{array}{c}\text { Dinheiro vivo } \\
\text { (agência de informação) }\end{array}$ & 1987 \\
\hline & Luis Nassif Online/GGN & 2005 \\
\hline Luiz Carlos Azenha & Viomundo & 2003 \\
\hline Miguel do Rosário & O Cafezinho & 2011 \\
\hline Paulo Henrique Amorim & Conversa Afiada & 2006 \\
\hline \multirow{3}{*}{ Renato Rovai } & Publisher Brasil & 1995 \\
\hline & Revista Fórum & 2001 \\
\hline & Blog do Rovai & 2005 \\
\hline
\end{tabular}

Fonte: autoria própria

Em relação ao grau de institucionalização, são entendidos como menos institucionalizados aqueles empreendimentos em que há o acumulo de papéis por apenas um indivíduo, em contraste com a existência de estruturas (pré)organizacionais mais definidas com divisões de funções, adoção de normas internas de procedimento, sendo nesses últimos mais identificáveis traços de burocratização (sobre esse processo, abordando especificamente o desenvolvimento organizacional em blogs, ver LOWREY et al., 2011). Há, portanto, uma pluralidade de frentes de ação, de formas de produzir e existir institucionalmente na BP: do indi-

${ }^{2}$ Altamiro Borges também é secretário de Mídia do PCdoB, que tem o portal Vermelho. 
vidual (como o blog do Miro) para o coletivo (a exemplo do Intervozes e do Mídia Ninja); com iniciativas que adotaram maior institucionalização e/ou se tornaram de cunho empresarial (Conversa Afiada, Luis Nassif Online, Portal Fórum), ou que se caracterizaram por defender um projeto de jornalismo independente, inclusive no tocante a financiamento, como veremos (Viomundo, por exemplo); e aquelas vinculadas a partidos políticos, funcionando como mídia partidária (Vermelho).

Então, você tem nesse nosso ecossistema de mídia livre, você tem aí as iniciativas individuais que você pode caracterizar isso aí como os blogs. Você tem as articulações mais vinculadas a projetos de coletivos, coletivos que se articulam para fazer comunicação. A gente pode falar do Mídia Ninja que é um dos precursores, não bem precursor... eles foram muito importantes para o salto que se deu ali, né, em 2013. Aí você tem entidades sindicais que começam a perceber que é importante fazer produtos de comunicação e passam a ter um espaço não mais conduzido propriamente para sua entidade, como você tem a Rede Brasil Atual, que tem uma rádio agora, tem a Revista do Brasil, tem o site vinculado a algumas entidades, mas produz comunicação com uma pegada. Você tem grupos de causas, vamos dar um exemplo: Geledés, que é uma mídia negra, o Intervozes... e eles passam a ter sites, blogs, enfim, a partir dessas causas dos movimentos deles. E você tem produtos organizados de uma maneira empresarial sem ser a lógica empresarial pura e simples do lucro, mas como produto, como uma causa. Então a gente trabalha nesse segmento. Eu tenho uma empresa, uma editora que faz a Fórum, então eu sei que, por exemplo, o Conversa Afiada, apesar de ser um blog lá do Paulo Henrique, ele tem uma empresa. Para fazer - Conversa Afiada ele contrata pessoas, paga salário. É um outro tipo de iniciativa, como a da Fórum. ${ }^{3}$

Ainda no que diz respeito ao financiamento, também foi consultado o banco de dados disponibilizado pela Fundação Ford (relativo a funding/grants) a partir do primeiro ano disponível (2006) até o impeachment de Dilma Rousseff, em 2016. Nesses dados, buscou-se mapear quais agentes relacionados à rede da BP receberam fundos de natureza institucional privada ao longo do período pesquisado - ali não foram identificados blogs ou iniciativas de cunho individual, mas projetos coletivos de mídia alternativa, como Agência Pública, Fórum Nacional para a Democratização da Comunicação (FNDC), Geledés e Intervozes.

\footnotetext{
${ }^{3}$ Entrevista concedida à autora por Renato Rovai em 2016.
} 


\section{Mídia alternativa no Brasil e a construção do ethos profissional do jornalismo}

A BP é um fenômeno midiático que reúne jornalistas, movimentos sociais, ativistas políticos, intelectuais, sindicatos, entre outros; e, para cada um desses agrupamentos e suas respectivas formas de atuar através e enquanto mídia, poderíamos utilizar uma nomenclatura diferente (cf. WATSON; HILL, 2003): imprensa alternativa para o primeiro grupo; mídia ativista ou ciberativista para o segundo; mídia underground para aqueles mais relacionados à contracultura (cientes de que, nos tempos da ditadura esta era uma forma possível de referência à "imprensa alternativa" que atuasse clandestinamente); jornalismo de combate ou radical para todos os já mencionados. Além disso, em boa medida, os estudos sobre mídia alternativa a conectam a perspectivas relacionadas à tradição anarquista (ATTON, 2001). Cada uma dessas denominações é, ao mesmo tempo, válida - a depender da interpretação - e insuficiente para dar conta de, simplesmente, por meio de uma expressão, compreender toda a complexidade da BP.

[...] mídia independente, mídia livre, mídia alternativa [...] você tem compreensões diferentes. Tem gente que chama de mídia tática, tem várias denominações. [...] O Raimundo da Repórter Brasil costuma chamar de mídia popular. É o termo que ele acha que é mais adequado. Aí no caso do Raimundo tem muito a ver com a formação dele e as ligações dele com o partido comunista chinês. Então, a mídia alternativa é um termo que se tentou para o Brasil. Se não me engano foi o Alberto Dines, numa coluna que ele escrevia na Folha de S. Paulo, que usou pela primeira vez. Aí ele usa esse alternative media para falar dos veículos nanicos daquela década de 70, e ficou muito ligada àqueles veículos o termo, né!? E ficou muito ligada aos jornais tabloides. Por isso, quando a gente lança os nossos veículos e quer fazer um fórum deles lá atrás, que é o Fórum de Mídia Livre, coordenado aí por algumas pessoas, [Joaquin] Palhares, eu, a Ivana [Bentes], enfim, a gente acaba cunhando nosso movimento de fórum de mídia livre porque ele tem uma conexão maior com os movimentos de software livre, de rádio livre e da internet, que toda pauta era a lógica da liberdade, do livre, do free. Tem isso do free, o livre ele dá dois entendimentos: o do grátis e da liberdade. ${ }^{4}$

De modo abrangente, podemos dizer que "imprensa alternativa" ou "nanica" são expressões que se relacionam a um conjunto de agentes mais específicos ligados a pequenos empreendimentos jornalísticos não comerciais, particularmen-

\footnotetext{
${ }^{4}$ Entrevista concedida à autora por Renato Rovai em 2016.
} 
te (mas não exclusivamente) do meio impresso; essas expressões estão relacionadas a uma temporalidade, remetendo ao jornalismo "de resistência" durante o período militar. Já "mídia alternativa", acreditamos, congrega um conjunto maior e mais plural de atores, sendo uma terminologia mais adequada para nos referirmos aos projetos contemporâneos - que, em sua diversidade, sob múltiplos aspectos, apresenta maior abertura à alteridade, recepcionando também projetos comerciais que conjugam a aceitação do sistema capitalista com crítica ao poder opressor do mercado e ao liberalismo econômico enquanto política dominante. Com relação ao termo "alternativa", permanece atual a observação feita por Bernardo Kucinski ao se referir à imprensa do regime militar, de que o termo abarca quatro significados essenciais: "o de algo que não está ligado a políticas dominantes; o de uma opção entre duas coisas reciprocamente excludentes; o de única saída para uma situação difícil e, finalmente, o de desejo das gerações dos anos de 1960 e 1970 de protagonizar as transformações sociais que pregavam" (KUCINSKI, 2001, p. 5).

A afirmação em torno da emergência de novos modelos de jornalismo, sobretudo na web, está relacionada também aos avanços tecnológicos que viabilizaram a implementação de projetos jornalísticos alternativos a baixo custo e desvinculados de organizações noticiosas. Fenômeno que não pode, porém, ser adequadamente compreendido como algo gestado exclusivamente em torno do potencial das relações sociotécnicas propiciadas pelo advento de certas tecnologias como "a internet", "os blogs" ou "as mídias sociais", mas como algo que se baseia em uma experiência prévia de jornalismo alternativo e que, a partir dos anos 2000, pôde se concretizar de modo mais contundente. Interessante notar que, em oposição a essa "nova ecologia" de mídia alternativa e como desdobramento desse processo, ganharam terreno, em paralelo, grupos de produção de informação "antimainstream" e "antialternativos" e vários casos associados a redes de desinformação, em particular na segunda metade da década de 2010, a partir das manifestações de 2013 e da permanência do PT à frente da presidência da república, com a reeleição de Dilma Rousseff em 2014, quando ganharam contorno e proeminência redes de ciberativismo político vinculadas ao espectro de direita e extrema direita (cf. ALBUQUERQUE et al., 2015; ALVES, 2019). Assim, as experiências contemporâneas de mídia trazem consigo alguns dilemas e merecem ponderações.

Não obstante, a formação da atual ecologia de mídia alternativa no Brasil é parte de um processo histórico que começou décadas atrás. Embora paradoxal 
à primeira vista, o "jornalismo sem jornal" (DE MAGALHÃES CARVALHO; ALBUQUERQUE, 2014), empreendido desvinculado de grandes empresas jornalísticas, foi o modelo predominante de jornalismo praticado no país ao longo de praticamente todo o século XIX - embora no caso isso se devesse antes à incipiência de recursos físicos e organizacionais de uma produção artesanal do que a uma opção consciente. Em sua enorme maioria, os veículos jornalísticos do período oitocentista consistiam de panfletos políticos redigidos por uma única pessoa, com pequenas tiragens, produção irregular e vida curta (cf. LUSTOSA, 2000; RIBEIRO, 2007). De fato, a institucionalização do jornalismo brasileiro foi um processo lento, que se desenrolou ao longo do século passado e cuja forma moderna remete às reformas jornalísticas da década de 1950. Na década seguinte, o modo de se entender e se praticar o jornalismo no Brasil começou a mudar, motivado sobretudo por questões comerciais. Nas redações brasileiras, passou-se a privilegiar a informação em detrimento da opinião, ao menos "proforma"; esta última encontrava-se separada graficamente das notícias propriamente ditas. Nos anos que se seguiram, a evolução rumo ao "jornalismo comercial" trouxe mudanças menos visíveis ao grande público, mas que marcaram um ethos profissional. O processo de modernização implementado pelos donos de jornais, tanto no Brasil quanto nos Estados Unidos, envolveu a redução de custos e a defesa de interesses comerciais, muitas vezes imbricados ao noticiário - apesar de ressaltada a separação formal entre esses departamentos.

Nos anos de 1970, a introdução de computadores nas redações norte-americanas já havia mudado profundamente o ambiente profissional antes mesmo da web entrar em cena no dia a dia dos jornais. "As relações entre o negócio e os lados editoriais dos jornais foram desfocadas. Pedia-se aos jornalistas que fizessem mais com menos e com menos autonomia" (RYFE, 2012, p. 41). No Brasil, essas mudanças contribuíram para nutrir um ideal de "jornalismo sem jornal”, pelo menos na dimensão corrente de jornal enquanto organização capitalista, voltada para a obtenção de lucro. Segundo essa perspectiva, que encontrou o seu caráter exemplar na experiência da imprensa alternativa, que teve lugar no país durante o regime militar que vigorou entre 1964 e 1985, o jornalismo só seria realmente praticado longe das empresas de notícia, porque dentro delas não haveria liberdade ou autonomia para tal.

Podemos identificar, assim, alguns fatores que contribuíram para o desenvolvimento da imprensa alternativa entre os anos de 1960 e 1980: o processo de 
modernização das redações; a censura vinda de fora; e as restrições impostas pelos próprios jornais (cf. DANTAS, 2014; DIAS, 2012), que limitavam a produção intelectual dos jornalistas, algo relacionado à perseguição à "esquerda política", incluindo partidos clandestinos e sindicatos. "A imprensa alternativa surgiu da articulação de duas forças igualmente compulsivas: o desejo das esquerdas de protagonizar as transformações que propunham e a busca, por jornalistas e intelectuais, de espaços alternativos à grande imprensa e à universidade" (KUCINSKI, 2001, p. 6). Esses fatores que se relacionam, em essência, à construção de todo um imaginário em torno da atividade jornalística e se vinculavam à noção de independência, que aqui é considerada, principalmente, em três sentidos: primeiramente, e mais basilar para o ethos profissional, de que o verdadeiro jornalismo só se daria mediante a autonomia do jornalista para apurar e escrever suas reportagens; de que não teria vínculo partidário ou ideológico; e de que era fundamental para um meio de comunicação não ficar na esteira de interesses econômicos ou políticos, com a independência sendo alcançada desvinculando-se à atividade jornalística de patrocinadores, financiadores e/ou anunciantes que pudessem exercer pressão sobre o trabalho da imprensa.

As novas tecnologias trazidas pela evolução da internet facilitaram não apenas a realização de um jornalismo desvinculado das organizações noticiosas como, paradoxalmente, a aproximação de jornalistas com o negócio de fazer jornal - agora compartimentado em uma categoria positiva, um dos desdobramentos do ideal de "libertação" do jornalista do assalariamento, dos constrangimentos que fazem parte do dia a dia das redações e, por fim, das amarras do jornal enquanto empresa (LIMA, 2015). Na segunda década de 2000, muitos desses agentes que migraram para a blogosfera passaram a acumular também perfis em redes sociais, ao lado de outros recém-chegados ao mercado midiático on-line. A segmentação político-ideológica do mercado de notícias, por sua vez, é algo que faz bastante sentido (cf. STROUD, 2011; ALBUQUERQUE; DE MAGALHÃES CARVALHO; LYCARIÃO, 2018) e que se insere na lógica de redes sociais, uma vez que o conteúdo disseminado on-line tende a ficar represado em "bolhas" ideológicas.

\section{Mudanças em curso na topografia midiática}

A última década foi marcada pelo reconhecimento de meios fora do mainstream (ou que se posicionam como alternativos a ele) como fonte de informa- 
ção. E isso se dá, em boa dose, mediante a necessidade menos latente e mais manifestada de públicos que procuram informações para alimentar discussões e reforçar pontos de vistas (STROUD, 2011). Ainda na década de 1990, inicia-se uma acentuada queda na confiança no jornalismo (RYFE, 2012, p. 36; PEW RESEARCH CENTER, 2016), um processo de perda de credibilidade que contribuiu para o declínio dos jornais diários ao longo do globo, abalando e mesmo pondo em xeque o lugar do jornalista enquanto autoridade informativa (CARLSON, 2007). O Brasil está inserido nesse cenário de mudanças, sendo notável a explosão dos blogs de política em meados dos anos 2000 (ALDÉ; CHAGAS; ESCOBAR, 2008), acompanhando um fenômeno que já se desenvolvia nos EUA. Em 2010, uma pesquisa feita pela Technorati com consumidores sobre confiança nos meios de comunicação apontou que $40 \%$ concordavam com o ponto de vista dos blogueiros, enquanto demonstravam ter menos confiança na mídia mainstream.

Entendemos o ciberespaço, portanto, como um ambiente dinâmico, em que sites e blogs são criados com a mesma velocidade que são desativados - ou seja, é relativamente fácil colocar uma página no ar, porém conquistar longevidade e credibilidade na web já é algo mais difícil de ser alcançado. Desde o surgimento dos primeiros blogs de política, ainda na primeira metade dos anos 2000, a internet se expandiu no Brasil. Entretanto, como nos lembra Fuchs (2010, p. 178), um cenário de mídia diversificado, no qual cada consumidor pode se tornar um produtor midiático, não constitui automaticamente uma democracia da mídia, principalmente se apenas alguns têm acesso de fato ao que está sendo dito de diferente.

No Brasil, o número de pessoas conectadas à internet vem aumentando, estima-se o montante de 118 milhões de usuários individuais em 2014, 132 milhões em 2015 e pouco mais de 139 milhões em 2016. E isso se refletiu no processo de migração de verbas de publicidade e outras fontes de financiamento para o ambiente on-line. 0 crescimento de segmentos alternativos no sistema midiático brasileiro é parte do processo de expansão do universo on-line. Há mais canais de comunicação (blogs, sites, perfis/páginas em redes sociais e plataformas on-line), maior competitividade, trabalho conjunto e mesmo canibalização dentro de nichos cada vez mais específicos. Em 2017, apenas no site do Barão de Itararé, entidade representativa dos blogueiros progressistas, havia listados 229 blogs ligados à rede progressista; em contrapartida, naquele mesmo ano, ganhavam mais vigor as redes de extrema direita no Brasil, fomentadoras de polarização política no país. 


\section{Discutindo o financiamento da mídia alternativa brasileira}

Nas décadas que se seguiram à abertura política no país, é possível identificar jornalistas investindo na experiência alternativa, dentre eles alguns dos entrevistados neste trabalho. Luis Nassif criou a agência de informação Dinheiro Vivo em 1987; Renato Rovai, na década de 1990, montou a Publisher Brasil, empresa voltada para o segmento progressista. Ambas as iniciativas continuam em exercício, se fazendo presentes também na web e sendo exemplos de empreendimentos institucionalmente mais estruturados. A Revista Fórum, criada por Rovai em 2005, conta com "um projeto editorial e um projeto comercial", segundo Rovai. Em 2013, a revista se transformou em um portal e passou a contar com mais colaboradores, abarcando inclusive alguns blogueiros do núcleo duro da BP, como Conceição Oliveira (blog Maria Frô) e Rodrigo Vianna (blog Escrevinhador).

A gente é muito amigo. Eu falei: "Se vocês quiserem hospedar lá, vocês colocam o blog e passam a não ter nenhum tipo de custo. Se tiver algum recurso pro site de vocês, a gente repassa". Uma discussão muito mais pautada, porque para eles acabava tendo custo do site; você tinha que fazer uma alteração, aí tinha que contratar um programador, tinha que pagar o domínio, tinha que pagar o servidor. Então, tem toda uma relação de comodidade e, qualquer coisa que eles pedem, a gente faz: tem o pessoal de suporte nosso e tem planos de terminada essa fase agora, eu vou conversar com mais gente pra ampliar esse nosso, digamos assim, time de blogueiros. ${ }^{5}$

O Conversa Afiada, criado por Paulo Henrique Amorim no início dos anos 2000, também conta com uma modesta estrutura empresarial, o que inclui uma diretora executiva (o site continua no ar, apesar de ter encerrado as atividades um ano após a morte de P.H. Amorim, em julho de 2019). Interessante observar que, no campo progressista, há a Associação Brasileira de Empresas e Empreendedores da Comunicação (Altercom), cuja fundação em 2010 foi protagonizada por Joaquim Palhares (Carta Maior) e Renato Rovai. A instituição congrega pequenas empresas e empreendedores individuais de comunicação, como os blogueiros progressistas Eduardo Guimarães (Blog da Cidadania), Luiz Carlos Azenha (Viomundo), Marcelo Salles (Fazendo Media), Marco Aurélio Weissheimer (RS Urgente) e Rodrigo Vianna (Escrevinhador), e possui como objetivo, segundo seus fundadores, representar empresas e empreendedores de comunicação comprometidos com a democratização do setor.

\footnotetext{
${ }^{5}$ Entrevista concedida à autora por Renato Rovai em 2016.
} 
O financiamento das iniciativas da BP se volta para viabilizar a manutenção da existência desses agentes no sistema midiático, seja provendo algum retorno para o sustento de seu responsável, seja garantindo a periodicidade das postagens, o pagamento de colaboradores e funcionários - no caso de empreendimentos mais elaborados - ou a realização de trabalhos jornalísticos que exigem mais recursos, como reportagens de cunho investigativo. Basicamente, identificam-se financiamentos de duas naturezas: 1) externos ao blog, site ou outro tipo de iniciativa midiática - ou seja, recursos provenientes de verbas públicas ou da iniciativa privada, seja ela empresarial ou fruto de subvenção concedida por instituições de fomento, em geral, internacionais; e 2) relacionados a estratégias de autofinanciamento, a partir de esforços do próprio veículo de comunicação em gerar recursos para se manter economicamente viável. As principais fontes de recursos dos agentes relacionados à BP são obtidas por meio de: a) publicidade; b) patrocínio; c) instituições privadas sem fins lucrativos; d) movimentos sociais/sindicais ou partidos políticos; e) "vaquinhas coletivas" (crowdfunding); f) assinatura (cobrança de assinatura sobre conteúdos); g) oferta de serviços, como cursos de formação; e h) venda de material editorial (Tabela 2).

\section{Tabela 2 - financiamento da mídia alternativa no Brasil}

\begin{tabular}{|c|c|c|}
\hline $\begin{array}{c}\text { ORIGEM DO } \\
\text { FINANCIAMENTO }\end{array}$ & \multicolumn{2}{|c|}{ FONTES/ESPECIFICIDADES } \\
\hline \multirow{6}{*}{ Externa } & \multirow{3}{*}{ Publicidade } & Administração pública \\
\hline & & Setor privado \\
\hline & & Contrato com Google \\
\hline & \multicolumn{2}{|c|}{ Patrocínio } \\
\hline & \multicolumn{2}{|c|}{$\begin{array}{c}\text { Doações (funding/grants) - via instituições privadas sem } \\
\text { fins lucrativos }\end{array}$} \\
\hline & \multicolumn{2}{|c|}{ Partidos/Sindicatos } \\
\hline \multirow{4}{*}{ Autofinanciamento } & \multicolumn{2}{|c|}{ Crowdfunding } \\
\hline & \multicolumn{2}{|c|}{ Assinaturas } \\
\hline & \multicolumn{2}{|c|}{ Serviços/Realização de eventos } \\
\hline & \multicolumn{2}{|c|}{ Venda de material editorial } \\
\hline
\end{tabular}

Fonte: Autoria própria

O crowdfunding está muito relacionado ao ideal de jornalismo independente, de serviço de interesse público financiado pelo povo - neste caso, relacionado à própria audiência do veículo (cf. CARVAJAL; GARCÍA-AVILÉS; GONZÁLEZ, 2012). Apesar de a cobrança de assinatura para acesso ao conteúdo ser questionável no 
âmbito do movimento midialivrista, a iniciativa de autofinanciamento não costumam ser foco de críticas. Em geral, geram mais controvérsias as origens externas de financiamento, cujas fontes de recursos são passíveis de serem associadas a ameaças em potencial à verdadeira liberdade de imprensa, via controle financeiro exercido por governos ou entidades ligadas ao modelo liberal de economia. O principal ponto em questão é a busca por independência e autonomia profissional historicamente construída e que faz parte do ethos profissional do jornalismo no Brasil.

Em linhas gerais, se o verdadeiro jornalismo possui como finalidade principal a defesa do interesse público, essa vocação poderia ser ameaçada pelo poder econômico exercido por grandes empresas (grandes anunciantes) ou outras expressões institucionais, como governos (via publicidade pública) e mesmo entidades sem fins lucrativos, como fundações (por meio de doações - funding ou grants). Apesar de contribuir para tornar viável a atividade jornalística, esses tipos de fontes de recursos esbarram em questões éticas e apresentam dilemas para os empreendimentos jornalísticos: ficar em "débito" para com os anunciantes, sejam eles públicos ou privados (DOWNIE JR.; SCHUDSON, 2009); ou o risco de se tornar parte de programas ideológicos de grandes fundações (em particular think tanks), agindo como expressões de soft power de entidades sem fins lucrativos, como a Fundação Ford e a Open Society.

De acordo com o material coletado a partir das entrevistas, as principais formas de geração de capital de iniciativa, quase que exclusiva, dos blogueiros são: o estabelecimento de parcerias com grandes empresas como Google, em que o blogueiro "vende" espaços publicitários de sua página ao Google, recebendo conforme o número de "cliques" obtidos; a cobrança para acesso ao conteúdo do blog, site ou portal, mediante política de assinaturas; o recebimento de contribuições, como "vaquinhas virtuais" ou crowdfunding, que se tornaram bastante populares no ambiente alternativo; a participação ou realização de eventos, o que inclui seminários, palestras e cursos, em que é cobrado um valor para participar; a venda de livros; e o patrocínio, obtido via de regra de entidades ligadas à administração pública6 ${ }^{6}$ Em geral, o que ocorre é o embaralhamento ou a alternância dessas iniciativas como meio de sobrevivência econômica da mídia alternativa, como discutiremos a seguir.

\footnotetext{
${ }^{6}$ Cabe mencionar que as fontes de financiamento apontadas não excluem outras formas passíveis de serem adotadas, como o financiamento via editais públicos, aqui não contemplado por não se evidenciar expressivo no universo pesquisado.
} 


\section{Os financiamentos a partir de grandes players}

Historicamente, os recursos provenientes de publicidade, seja ela pública ou privada, são encarados tanto como libertadores quanto aprisionadores do jornalismo, dependendo do peso que têm no balanço orçamentário da atividade jornalística. Em paralelo, quanto mais se profissionaliza um projeto de jornalismo alternativo e independente, maior tende a ser sua necessidade por recursos para se manter em atividade. O site Conversa Afiada, por exemplo, à época da entrevista com Paulo Henrique Amorim, informou que contava com "um plano de assinaturas, contrato com o Google e publicidade de empresas privadas" para financiar sua modesta estrutura e se manter em atividade. Cabe notar que normalmente é preciso ser um meio de comunicação já proeminente para conseguir fechar contratos mais expressivos de financiamento - e não o contrário -, o que tende a levar a discussão para o terreno da participação de instituições públicas no fomento de novas iniciativas de mídia alternativa.

Em linhas gerais, a concentração midiática no Brasil se traduziu, também, em concentração de investimentos via recursos públicos, em poucos grupos de mídia, que em geral se vinculam a posições conservadoras e economicamente liberais. 0 governo, em particular a administração pública federal, é um grande financiador de mídia no Brasil, fazendo-se bastante presente no mercado da comunicação do país. Sua principal forma de alocação de recursos em empreendimentos jornalísticos se faz via publicidade - sendo também possível obter financiamento público via patrocínio proveniente de entidades da administração pública indireta, por exemplo, ou por meio da participação em concorrências via edital.

Falei em público a respeito no I Encontro de Blogueiros, em 2010, em São Paulo. Alertei então os colegas sobre o risco de criar dependência de verbas de publicidade exclusivamente de governos, sejam quais fossem. Na ocasião, sugeri que se formasse uma cooperativa de blogueiros para vender publicidade coletivamente no mercado. Porém, eu, ingenuamente, não tinha me dado conta de dois fatos: 1) há um tremendo preconceito ideológico do 'mercado' brasileiro contra a opinião de esquerda; 2) as verbas de publicidade no Brasil não migraram para a internet com a rapidez que eu tinha visto migrarem nos Estados Unidos. O que sempre defendi é que haja política pública para incentivar novos produtores de conteúdo, o formato é algo a discutir.?

\footnotetext{
${ }^{7}$ Entrevista concedida à autora por Luiz Carlos Azenha em 2016.
} 
Para os blogueiros, o incentivo que se concretizaria não somente - ou necessariamente - através de financiamento público, mas de uma série de medidas que poderiam ter sido adotadas com o fito de promover uma real democratização do sistema de mídias no país.

Por exemplo, você ter um programa de internet barata. Para a gente isso seria fantástico, a internet barata. Você criar leis que estimulassem empresas de publicidade a anunciar na internet. 0 Brasil, até hoje, o seu percentual de publicidade na internet é muito aquém do que é a internet brasileira, porque você tem um mercado de publicidade sequestrado por grandes grupos de mídia. Então, o percentual que vai para a televisão, no Brasil, é superior ao que existe em outros países. ${ }^{8}$

A expectativa dos blogueiros progressistas jamais chegou a se concretizar plenamente. Durante as gestões do Partido dos Trabalhadores (PT), houve um aumento de investimentos em publicidade governamental em mídia sem, porém, a distribuição dessas verbas acompanhar o processo de renovação do sistema midiático brasileiro (DE MAGALHÃES CARVALHO, 2020). Além disso, a BP, enquanto movimento pela democratização das comunicações no Brasil, sofreu um duro golpe em 2016, com os cortes do financiamento a mídias consideradas "progressistas" ou "de esquerda" promovidos por Michel Temer logo que assumiu a presidência da República - sendo o repasse de recursos do governo federal a sites e blogs desse segmento zerado a partir de junho daquele ano.

Como o problema em relação ao financiamento não se circunscreve à publicidade em si, mas à sua fonte, a questão também abarca verbas recebidas de outras procedências institucionais, como fundações sem fins lucrativos consideradas de fomento à democracia (em geral, entidades estrangeiras). Cumpre enfatizar que qualquer recurso advindo de algum "grande player" é fonte potencial de desconfiança, em virtude do impacto que seu recebimento pode proporcionar à "imparcialidade" ou independência da atividade jornalística.

Então, você tem duas, três ditaduras... e são ruins, né?! A ditadura do dono do jornal, a ditadura do patrocinador e a ditadura desse leitor engajado que quer te colocar como um soldado e não como jornalista. Então, por isso que eu também não gosto dessa caracterização de "blogueiro progressista", que pegou, infelizmente, né. Enfraqueceu... enfraqueceu o discurso. O que fortalece a crítica jornalística é quando você vem no momento da crítica. No momento em que você faz o elogio, aí é chapa-branca. Então enfra-

${ }^{8}$ Entrevista concedida à autora por Miguel do Rosário em 2017. 
queceu muito! Quando começou essa questão de blogueiros progressistas e tudo, houve uma instrumentalização por parte dos partidos políticos aí. Nós tivemos aqui os nossos...9

No caso de financiamentos oriundos de partidos políticos, como a fala de Nassif deixa ver, sobre seu recebedor haverá a sombra de "chapa-branca" ou "cooptado". Particularmente, a crítica quanto à instrumentalização (ou tentativa de instrumentalização) da mídia alternativa costuma recair bastante sobre páginas progressistas que receberam financiamento oriundo do governo federal durante as administrações do PT, caracterizando-se mais como uma ação do governo que do partido propriamente dita, o qual também possui meios próprios de interação com a rede, como o site PT na Câmara. Apesar das críticas, ressalta-se, o PT não priorizou a mídia alternativa na distribuição das verbas de publicidade durante os anos que passou à frente da administração federal. Sobre o PCdoB e a relação com veículos de mídia alternativa, Altamiro Borges, que também é secretário de mídia do partido, esclarece que não houve recursos destinados ao movimento.

O PCdoB tem um site, que é o Vermelho ${ }^{10}$. Aí sim, é um site do PCdoB onde os jornalistas são contratados pelo PCdoB, que produz conteúdo legal, respeitado por todo mundo e tal. Agora, de financiar outros, talvez não é nem que não houvesse vontade, é que não tem é dinheiro. ${ }^{11}$

Já o financiamento vindo de fontes ligadas ao "mercado" ou a instituições de fomento identificadas com o modelo liberal econômico, a exemplo da Fundação Ford e da Open Society Foundations, funcionaria, aos olhos de muitos blogueiros e outros ativistas, como uma contaminação nociva ao movimento, conflitando interesses particulares defendidos por essas instituições com o interesse público. De fato, há estudos que apontam que o fomento por meio de doações seria uma forma simbólica de persuasão, ajudando a formar lideranças ou elites políticas (sejam elas midiáticas ou acadêmicas) e apoiando ideologias segundo interesses particulares (cf. ALBUQUERQUE; PAULA, 2017; BROWNE, 2010; FELDMAN, 2007; SANTOS-ROCHA, 2015).

Assim, essas instituições funcionariam como importantes componentes para a manutenção de estruturas de controle por parte de elites já estabelecidas.

\footnotetext{
${ }^{9}$ Entrevista concedida à autora por Luis Nassif em 2016.

10 Mais que um site, o Vermelho tornou-se um portal do PCdoB, ao qual se vincula, entre outras iniciativas, a já tradicional editora Anita Garibaldi, criada em 1979.

${ }^{11}$ Entrevista concedida à autora por Altamiro Borges em 2016.
} 
Nesse sentido, a Fundação Ford, por exemplo, pode ser entendida "como uma organização dedicada aos processos de engenharia social, cujas metas estão relacionadas à fabricação de ideologias e consensos entre as elites intelectuais, para institucionalizar parâmetros de atuação de acordo com diretrizes norte-americanas" (SANTOS-ROCHA, 2015, p. 182). No caso de movimentos sociais e apoio a entidades não governamentais, o financiamento institucional teria como objetivo "ajudá-las a tornarem-se organizações dominantes no movimento e orientar os movimentos sociais em direções seguras, não interferindo na atuação das elites políticas, industriais e financeiras" (ibid., p. 182); perspectiva que é adotada em parte por alguns responsáveis por veículos de mídia alternativa sobre colegas financiados por essas instituições - ponto de vista explicitado em conversas informais das quais a autora participou em eventos em que esteve presente.

Em linhas gerais, uma das principais questões enfrentadas pelos recebedores de fomento é congregar multiplicidade de fontes de recursos, estabilidade no recebimento desses insumos e manutenção da integridade jornalística. De acordo com um estudo da Columbia Journalism Review (CJR), citado por Drew (2010), cerca de US\$ 143 milhões foram doados por fundações a empresas de mídia no mundo todo entre 2005 e abril de 2010, sendo mais da metade desse montante destinado a 12 organizações voltadas ao jornalismo investigativo. No Brasil, entre os receptores mais expressivos desta seara estão entidades que são ou têm se tornado relevantes na rede progressista, como o Fórum Nacional para a Democratização da Comunicação (FNDC), o coletivo Intervozes e, mais recentemente, a Agência Pública. São agentes que, em boa medida, contribuem para compor e moldar o debate em torno da democratização da comunicação no país, pari passu a uma atuação em defesa da independência jornalística.

\section{Estratégias de autofinanciamento: entre o "lugar perfeito" e o viável}

A colaboração para a produção e circulação de conteúdo é uma das características da BP, uma forma de atuação que ajuda a definir os contornos da rede progressista, mas que funciona também no que tange ao aspecto micro, no modo como várias dentre as mídias que compõem esse ecossistema trabalham internamente, em seus blogs, sites ou outros canais de comunicação. Luis Carlos Azenha e Conceição Lemes, por exemplo, são responsáveis pelo Viomundo. Mas a atividade da página não se encerra neles, há mais pessoas que, de alguma forma, contribuem com o trabalho na página. 
Todos os leitores são, de alguma forma, contribuintes. Portanto, somos milhares, com dezenas de contribuições diárias via redes sociais de textos, imagens, fotos, memes, sejam dos próprios leitores, sejam de terceiros. Temos colunistas informais, pessoas que periodicamente nos oferecem textos para disseminação, além de uma ampla rede de contatos nos movimentos sociais. ${ }^{12}$

Em 2015, o Viomundo, que até então se mantinha no campo da resistência ao recebimento de verbas não vinculadas ao público leitor do blog, apostando particularmente em estratégias de crowdfunding para o financiamento de projetos jornalísticos e mantendo livre acesso ao conteúdo da página, decidiu ampliar a fonte de recursos para sua manutenção, profissionalizando a parte administrativa do blog.

Uma ação judicial em três esferas pode custar hoje, com um bom advogado, 30 mil reais. Fora os custos de eventual condenação. Calculo que ao longo da existência do blog coloquei mais de 300 mil reais de dinheiro próprio, de salário, para mantê-lo no ar, incluindo todos os custos, sem considerar minha própria mão de obra. Como chegamos a uma situação limite, a parte comercial do Viomundo passou a ser gerida pela agencia Café Azul, com liberdade para fazer campanhas de assinatura e arrecadação junto a leitores, fazer um acordo com o Google, fechar parcerias com movimentos sociais/sindicatos e, sim, ficar à disposição do mercado publicitário, público ou privado. Porém, nunca batemos na porta de anunciante, nem público nem privado. Fomos incluídos, junto com dezenas de outros meios, inclusive da mídia corporativa, em algumas campanhas publicitárias do governo federal, nada próximo dos R\$ 500 milhões anuais da TV Globo. Se você fizer a conta pelos 15 anos de existência do blog, dá menos de 10 mil reais por ano, isso mesmo, menos de 10 mil reais por ano! Por que, no entanto, vemos colegas que receberam quantias mais significativas serem denunciados como "chapa-branca" pela mídia corporativa, que recebe em publicidade oficial bilhões e bilhões? Porque o objetivo é calar as vozes dissidentes do discurso único. É impedir que elas produzam conteúdo próprio. Conteúdo próprio, para além da opinião, é a verdadeira liberdade na blogosfera: poder pagar a um repórter e a um fotógrafo por uma reportagem investigativa, por exemplo. Escapar da prisão que faz com que os jornais de Roraima reproduzam noticiário produzido em São Paulo sobre Roraima. Uma blogosfera com capacidade econômica para fazer isso, essa é a grande ameaça ao jornalismo da meia dúzia de famílias que controlam a mídia brasileira, os "31 Berlusconis", segundo relatório do Repórteres Sem Fronteiras. Hoje o Viomundo é mantido pela Café Azul através da contribuição de leitores/Google/venda de livros. ${ }^{13}$

12 Entrevista concedida à autora por Luiz Carlos Azenha em 2016.

${ }^{13}$ Entrevista concedida à autora por Luiz Carlos Azenha em 2016. 
A venda de livros, nota-se, também é um meio de geração de renda explorado por alguns agentes pesquisados. O Portal Fórum, por exemplo, dispõe de uma editora, a Publisher Brasil. O Barão de Itararé, para o qual o investimento em publicações também constitui um meio de obter recursos, possui outras fontes de financiamento, como o recebimento de patrocínio para eventos, a exemplo do Seminário Internacional Mídia e Democracia nas Américas, realizado em 2015. Em entrevista, Altamiro Borges informa que o seminário contou com "10 países dos continentes para falar sobre mídia tradicional, mídia alternativa e democratização da comunicação em seus países. E esse evento teve o patrocínio da Caixa Econômica Federal"; segundo ele, fonte "que vai secar" - prevendo os impactos que de fato ocorreriam, a partir da gestão Michel Temer, no universo progressista brasileiro. O Barão de Itararé ainda conta com a promoção de atividades, como palestras, seminários, debates e oferta de cursos de formação, mediante cobrança de dinheiro para a participação. Outra proposta voltada para arrecadar fundos é a chamada "Os amigos do Barão", colaboradores que ajudam a instituição a concretizar ações.

Ajudam em um evento, ajudam em alguma publicação e tal. Esses são os amigos do Barão; e nesses amigos do Barão você tem pessoas jurídicas e tem pessoas físicas, então tem várias pessoas, tem gente que vem aqui doar dinheiro para o Barão todo mês, dá lá uma merrequinha que é belíssima, que ajuda a manter aqui a sede e tal. ${ }^{14}$

Também na segunda metade de 2010, o Conversa Afiada, até então mantido via publicidade de empresas do governo, empresas privadas, de acordos com o Google e serviços similares, alterou sua política de financiamento, aderindo à cobrança de assinaturas. E, durante muitos anos, a principal fonte de recursos d'O Cafezinho também foi a cobrança de assinatura para que o internauta tivesse amplo acesso ao conteúdo do blog.

O Cafezinho começa a usar isso muito parcimoniosamente. O que é a maioria, 90\%, foi post livre. E essa tensão entre o conteúdo exclusivo e o conteúdo livre sempre foi grande na internet e eu sempre usei o conteúdo exclusivo com muita parcimônia. Em algumas épocas eu usei mais conteúdo exclusivo, por exemplo agora não tô usando nada, agora eu abandonei essa estratégia na contramão dos outros blogs que tão entrando nessa área de conteúdo exclusivo na hora que eu tô saindo, entendeu? [...] e agora eu inaugurei uma estratégia nova que eu pensei no começo desse ano, tanto que deu certo, tá dando certo, que não é exatamente assinatura, embora também eu ainda use essa palavra assinatu-

${ }^{14}$ Entrevista concedida à autora por Altamiro Borges em 2016. 
ra. Mas é que são crowdfunding trimestral, entendeu? Eu vi que estava todo mundo fazendo crowdfunding, então pensei vou fazer um crowdfunding também. Só que eu faço esse crowdfunding pra sustentar o blog. ${ }^{15}$

O crowdfunding mencionado por Miguel do Rosário é uma estratégia bastante utilizada pela mídia alternativa. Mas, diferentemente da proposta do blogueiro, a "vaquinha coletiva" costuma estar presente nesses veículos para financiar a produção de matérias específicas (caso do Viomundo), cujos temas muitas vezes são escolhidos com a participação da audiência, por meio de sugestão ou votação. Neste trabalho, entendemos crowdfunding "como um processo relacionado ao financiamento de projetos ou empreendimentos usando o network para fazer uma chamada aberta e receber recursos financeiros da multidão" (CARVAJAL; GARCÍA-AVILÉS; GONZÁLEZ, 2012, p. 641). Sob esse aspecto, essa seria a política de financiamento que talvez mais se aproximasse dos ideais democráticos de jornalismo, uma vez que aponta para o protagonismo da audiência no processo de produção da notícia como "doadora de recursos", viabilizando o jornalismo em geral - e o investigativo em particular. Ao lado dos jornalistas, os leitores ocupariam o papel de definir o que será notícia, sem colocar em risco a qualidade do conteúdo, a cargo ainda dos repórteres, mas se tornando também uma espécie de gatekeepers (cf. AITAMURTO, 2011; CARVAJAL; GARCÍA-AVILÉS; GONZÁLEZ, 2012). Ainda adotando uma perspectiva democrática, nessa modalidade de financiamento os jornalistas manteriam o valor agregado de sua profissão ao moldar o que está sendo relatado e como isso é feito; e, ao menos em tese, trabalhariam abertamente e alcançariam seus objetivos paralelamente à aprovação de seus projetos jornalísticos pela audiência, por meio da doação de recursos. "Teoricamente, o crowdfunding trabalha como lugar perfeito para a conexão entre audiências e repórteres" (CARVAJAL; GARCÍA-AVILÉS; GONZÁLEZ, 2012, p. 646).

Porém, conseguir uma fonte de renda para a sustentabilidade de um empreendimento na internet, em meio à concorrência com as mídias tradicionais e com a pluralidade de veículos que ocupam também o ambiente virtual, não é fácil. Se o empreendimento for do segmento "alternativo" ou "progressista", maiores ainda os entraves. Essa é a perspectiva reforçada por Renato Rovai, que afirma: "rola um preconceito muito grande das agências de publicidade, do mercado, com veículos e produtos com as características da [Revista] Fórum". A alternativa para muitos blogueiros, principalmente aqueles que conquistaram menos visibilidade

15 Entrevista concedida à autora por Miguel do Rosário em 2017. 
no cenário midiático, é buscar renda a partir dos "cliques" dos internautas. O blog do Miro ilustra a questão: sem entrar em listas para recebimento de financiamento público ou do mercado publicitário, e com baixo potencial para obtenção de outros meios para subsidiar suas atividades, possui poucas chances de se tornar de fato um empreendimento jornalístico, continuando no segmento amador.

\section{Considerações finais}

No Brasil, a questão da democratização das comunicações defendida por agentes da mídia alternativa passa pelo terreno do financiamento das iniciativas midiáticas, como forma de viabilizá-las (não necessariamente comercialmente, mas fundamentalmente em termos de produção de conteúdo). As considerações em torno do recebimento de recursos provenientes de instituições de fomento se descolam de uma lógica partidária, mas também se associam a questões ideológicas mais amplas, como a vinculação ou não a entidades que defendam uma perspectiva liberal (mesmo que social-liberal). Nos Estados Unidos, por exemplo, em que o foco tende a se voltar às ameaças à independência jornalística representadas por corporações com fins lucrativos ou ao controle passível de ser exercido pelos governos, houve aumento substancial de financiamento à esquerda progressista por parte de fundações liberais a partir dos anos de 1990 (FELDMAN, 2007), tendo essas doações se tornado cada vez mais importantes e começado a chamar a atenção de pesquisadores. Foi também a partir desse período, no Brasil pós-abertura democrática, que a Fundação Ford, atuante no país desde 1962, passou a concentrar esforços em mídia e liberdade de expressão, entre outros assuntos relacionados a direitos humanos e de propriedade e recursos naturais.

Entretanto, o caso brasileiro insere-se em meio a disputas e discussões sobre o papel do capitalismo e a atuação imperialista norte-americana nas sociedades, podendo ser relacionado tanto à procura por autonomia como a um espírito revolucionário presente em várias dentre as iniciativas de mídia alternativa. Em linhas gerais, foram identificadas duas "naturezas" de financiamento utilizadas no seio da BP: 1) estratégias de autofinanciamento, a partir de esforços do próprio veículo de comunicação em gerar recursos para se manter economicamente viável; e 2) fontes externas ao blog, site ou outro tipo de iniciativa midiática, por meio de recursos provenientes de verbas públicas ou da iniciativa privada, seja ela empresarial ou fruto de subvenção concedida por instituições de fomento, em geral, internacionais. Enquanto as estratégias de autofinanciamento são bastante associadas ao ethos profissional do jornalismo no Brasil, ao aproximar a mídia do ide- 
al de independência necessária para o desenvolvimento do "bom" jornalismo, os recursos advindos do segundo grupo são os que costumam gerar maior controvérsia, cujas fontes são passíveis de serem associadas a ameaças em potencial à verdadeira liberdade de imprensa, via controle financeiro - seja ele exercido pelos governos ou pelas entidades privadas. É sobre essas formas de financiamento da mídia alternativa que este trabalho buscou lançar luz.

Ademais, a reconfiguração das dinâmicas de comunicação promovida pelos avanços da internet diluiu em alguma medida os dilemas apresentados em relação ao recebimento de financiamento ao amalgamar o ideal de jornalismo independente à formação de novas organizações noticiosas no campo alternativo de mídia. Ao apresentar o jornalismo como atividade em rede, em boa medida colaborativa entre os agentes e cuja ação se dá dentro de uma lógica de compartilhamento de notícias e pontos de vista em um ecossistema midiático, a BP proporciona a circulação da informação política, além da oportunidade para o ajuntamento de novos elementos que contribuam para seu aprofundamento on-line em termos de engajamento de agentes e promoção de perspectivas "novas" ou "alternativas" em um contexto altamente competitivo, cujo mercado é dominado por conglomerados midiáticos e disputado por novos players.

No Brasil, o jornalismo também tem passado por transformações não apenas de rotinas profissionais, principalmente no que tange à concentração cada vez maior de tarefas em um mesmo profissional (MORETZSOHN, 2014), mas também de percepção quanto ao papel social da profissão, além da alteração da própria topografia do sistema midiático do país, com novos atores se tornando relevantes no cenário da produção e veiculação de notícias e interpretações de acontecimentos. Se levarmos em consideração apenas a última década, foi posta em xeque não apenas a qualidade do jornalismo e sua relação com a democracia brasileira, como também o jornalismo e a própria democracia - em que o colapso democrático é apontando como sinal de tempos nebulosos (a exemplo de LEVITSKY; ZIBLATT, 2018). Como sobreviver e prosperar nesse cenário, portanto, é uma questão fundamental não apenas para os agentes responsáveis pelos meios de comunicação, mas também para a saúde da combalida democracia brasileira. Porém, não basta haver pluralidade de vozes e espaço para a dissonância. A questão do financiamento se faz importante porque impacta efetivamente no alcance que cada uma dessas iniciativas midiáticas alternativas pode ter para a promoção da democracia ou, ao contrário, ser sufocada economicamente em meio ao avanço de perspectivas autoritárias. 


\section{Referências}

AITAMURTO, T. The impact of crowdfunding on journalism: case study of Spot. Us, a platform for community-funded reporting. Journalism Practice, Londres, v. 5, n. 4, p. 429-445, 2011.

ALBUQUERQUE, A.; ALVES, M.; DE MAGALHÃES CARVALHO, E. Ciberativismo no Brasil: Blogosfera Progressista e rede antipetista. Cadernos Adenauer, São Paulo, v. 6, p. 75-96, 2015.

DE MAGALHÃES CARVALHO, E. Jornalistas sem jornal: a blogosfera progressista no Brasil. In: Anais do XXIIII Encontro Anual da Compós, p. 1-18. Belém, 2014.

A Blogosfera Progressista e a releitura do modelo de jornalismo independente no Brasil. In: NAPOLITANO, J.; VICENTE, M. M.; SOARES, M. C. Comunicação e Cidadania Política. Bauru: Cultura Acadêmica, 2017. p. 305-324.

; DE MAGALHÃES CARVALHO, E; LYCARIÃO, D. Noticiário "objetivo" em liquidação: a decadência do padrão "catch-all" na mídia comercial. Revista FAMECOS, Porto Alegre, v. 25, n. 2, p. 1-19, 2018.

PAULA, C. A. Accountability contra democracia: a comunicação política depois do golpe. In: Anais do VII Encontro da Compolítica, p. 1-29. Comunicação e Democracia. Porto Alegre, 2017.

ALDÉ, A.; CHAGAS, V.; ESCOBAR, J. A febre dos blogs de política. Revista FAMECOS, Porto Alegre, v. 14, n. 33, p. 29-40, abr. 2008.

ALVES, M. \#vaipracuba!: a gênese das redes de direita no Facebook. Curitiba: Editora Appris, 2019.

ATTON, C. Alternative Media. Thousand Oaks: Sage Publications, 2001.

BROWNE, H. Foundation-funded journalism: reasons to be wary of charitable support. Journalism Studies, England: University of Leeds, v. 11, n. 6, p. 889-903, set. 2010.

CARVAJAL, M.; GARCÍA-AVILÉS, J. A.; GONZÁLEZ, J. L. Crowdfunding and nonprofit media. Journalism Practice, v. 6, n. 5-6, p. 638-647, 2012.

CARLSON, M. Blogs and journalistic authority: the role of blogs in US Election Day in 2004. Journalism Studies. England: University of Leeds, v. 8, n. 2, 2007.

DANTAS, A. A mídia e o golpe militar. Estudos Avançados, São Paulo, v. 28, n. 80, p. 59-74, jan. 2014. 
DE MAGALHÃES CARVALHO, E. Financiamento da mídia no Brasil na era PT. E-Compós, v. 23, abr. 2020.

Jornalistas empreendedores: o segmento progressista brasileiro como nicho de mercado na web. Aurora, Pontifícia Universidade de São Paulo, v. 11, n. 32, p. 110-127, jun./set. 2018.

Jornalismo em rede: a blogosfera progressista como ecossistema midiático. Tese (Doutorado) - Instituto de Artes e Comunicação Social. Universidade Federal de Fluminense, 2017.

DIAS, A. B. 0 presente da memória: usos do passado e as (re)construções de identidade da Folha de S. Paulo, entre o "golpe de 1964" e a "ditabranda". Dissertação (Mestrado em Comunicação) - Setor de Ciências Humanas, Letras e Artes. Universidade Federal do Paraná, 2012.

DOWNIE JR., L.; SCHUDSON, M. The Reconstruction of American Journalism.

Columbia Journalism Review, nov./dez. 2009. Disponível em: https://archives.cjr. org/reconstruction/the_reconstruction_of_american.php. Acesso em: 13 jun. 2019.

DOWNING, J. Radical media: rebellious communication and social movements. Thousand Oaks: Sage Publications, 2001.

DREW, J. The new investigators: nonprofits are breaking new ground. Can they sustain themselves? Columbia Journalism Review, maio/jun. 2010. Disponível em: https://archives.cjr.org/feature/the_new_investigators.php. Acesso em: 10 jun. 2017.

FELDMAN, B. Report from the field: left media and left think thanks - foundationmanaged protest? Critical Sociology, Wayne State University, v. 33, n. 3, p. 427446, maio 2007.

FERREIRA, J. Prisioneiros do mito: cultura e imaginário político dos comunistas no Brasil (1930-1956). Niterói: Eduff; Rio de Janeiro: Muad, 2002.

FREITAS, E. L. V. Política e internet: 4 jornalistas (blogueiros) em novos tempos. Tese (Doutorado em Ciências Sociais) - Departamento de Ciências Sociais. Pontifícia Universidade de São Paulo, 2010.

FUCHS, C. Alternative Media as Critical Media. European Journal of Social Theory, v. 13, n. 02, p. 173-192, 2010.

GARSCHAGEN, B. A esquerda brasileira quer definir o que você pensa. E com dinheiro de bilionário americano. Extra, nov. 2016. Disponível em: https://extra. globo.com/noticias/brasil/sem-mimimi/a-esquerda-brasileira-quer-definir-quevoce-pensa-com-dinheiro-de-bilionario-americano-19988968.html. Acesso em: 23 fev. 2017. 
GUAZINA, L. Jornalismo que tem lado: o caso dos blogueiros brasileiros "progressistas". Brazilian Journalism Research, Universidade de Brasília, v. 9, n. 2, p. 68-87, dez. 2013.

KUCINSKI, B. Jornalistas e revolucionários: nos tempos da imprensa alternativa. 2. ed. São Paulo: Edusp, 2001.

LEVITSKY, S.; ZIBLATT, D. Como as democracias morrem. Rio de Janeiro: Zahar, 2018.

LIMA, C. C. N. Jornalistas, blogueiros, migrantes da comunicação: em busca de novos arranjos econômicos para o trabalho jornalístico com maior autonomia e liberdade de expressão. Tese (Doutorado em Ciências da Comunicação) - Escola de Comunicação e Artes. Universidade de São Paulo, 2015.

LOWREY, W.; MEADE, T; PARROTT, S. When blogs become organizations. Sage Journalism, v. 12, n. 3, p. 243-259, abr. 2011.

LUSTOSA, I. Insultos impressos: a guerra dos jornalistas na independência 18211823. São Paulo: Companhia das Letras, 2000.

MORETZSOHN, S. D. O "novo ritmo" da redação de O Globo. A prioridade ao jornalismo digital e seus reflexos nas condições de trabalho e produção da notícia. Parágrafo, São Paulo, v. 2, n. 2, p. 59-79, 2014.

PEW RESEARCH CENTER. State of the news media. 2016. Disponível em: www. stateofthemedia.org/2009/. Acesso em: 3 abr. 2021.

RIBEIRO, A. P. G. A imprensa da independência e do primeiro reinado: engajamento e mercado. In: Anais do INTERCOM - V Congresso Nacional de História da Mídia. História do Jornalismo. São Paulo, 2007.

RYFE, D. M. Can journalism survive?: an inside look at American newsrooms. Cambridge/Malden: Polity Press, 2012.

SANTOS-ROCHA, E. S. A Fundação Ford e o fomento para instituições estratégicas e lideranças acadêmicas no Brasil: análise sobre a parceria com a fundação Getúlio Vargas. Tese (Doutorado) - Instituto de Geociências. Universidade Estadual de Campinas, 2015.

STROUD, N. J. Niche News: the politics of news choice. New York: Oxford University Press, 2011.

WATSON, J.; HILL, A. Dictionary of Communication and Media Studies. 6. ed. New York: Oxford University Press, 2003. 